\title{
Panorama conjuntural das ações do setor petroquímico - Perspectivas para 2007
}

\author{
Breno Pascualote Lemos
}

\section{Introdução}

Apesar da recente instabilidade dos mercados financeiros mundiais, iniciada após a forte queda quase $9 \%$ na Bolsa de Xangai, o mercado acionário brasileiro apresentou um extraordinário desempenho desde a rodada liberalização financeira e o advento do Plano Real há quase 13 anos. De lá pra cá o índice Bovespa multiplicou-se por 13,2 $2^{48}$ Nesse mesmo período, por exemplo, a bolsa de Nova Iorque subiu cerca de 3,2 vezes. A atual instabilidade está menos para uma crise financeira do que para uma recomposição de carteiras e realização de lucros dos agentes ${ }^{49}$.

Em meio a este intenso crescimento da bolsa brasileira, as empresas que compõem o setor petroquímico ${ }^{50}$ experimentaram um forte crescimento, especialmente entre os anos de 1999 e 2004. Em 2005, o súbito aumento da cotação do petróleo e o novo patamar para os preços desta commodity, quase duas vezes maior do que o anterior, comprimiu suas margens de lucro e mudaram a tendência dos preços para seus papéis, os quais passaram a ir na contramão da tendência da bolsa.

O ano de 2006 foi de redução na lucratividade das empresas do setor e de reorganização frente ao choque de oferta negativo. As ações destas empresas seguiram em tendência de baixa, com seus papéis chegando a serem negociados abaixo de 50\% do pico de 2005. Ao mesmo tempo, muitos analistas recomendaram estes papéis, na crença de que se tratava de um período de realinhamento dos preços do petróleo - e que o preço do barril

\footnotetext{
* Professor Assistente do Departamento de Economia da PUC-PR e UFPR. Pesquisador do Grupo Macrodinâmica do Desenvolvimento. Endereço eletrônico: bplemos@uol.com.br .

48 Para maiores detalhes a respeito do comportamento da bolsa de valores de São Paulo entre os anos de 1995 e 2006, ver LEMOS (2007).

49 De fato, quando das crises financeiras nos países emergentes nos anos 90, o mercado de ações brasileiro passou por intensa instabilidade, oscilando negativamente mais de $40 \%$ no início delas, o que, combinado com o regime de câmbio fixo ou administrado na maior parte dos países emergentes e o baixo volume de reservas internacionais, causou fuga de capitais e ataques especulativos contra as moedas destes países. O Brasil, por exemplo, só não deixou o valor do real flutuar em 1997 porque promoveu um overshooting na sua taxa de juros nominal de curto-prazo.

${ }^{50} \mathrm{O}$ setor petroquímico transforma os derivados de petróleo e gás natural - como o nafta, o propano e o etano - nos mais diversos bens intermediários e finais. Basicamente, as empresas do setor se agrupam em três grupos ou gerações. O grupo da primeira geração faz o fracionamento do nafta e do gás natural, com o fim de obter os chamados produtos petroquímicos básicos (eteno e propeno). O grupo da segunda geração transforma os produtos petroquímicos básicos em produtos petroquímicos intermediários (estireno, por exemplo) ou finais (poliestireno, polietileno, polipropileno e elastômetros, por exemplo). Por fim, o grupo da terceira geração transforma os produtos das empresas de segunda geração em bens para o consumidor final (embalagens plásticas, pneus, brinquedos, autopeças, etc.).
} 
voltaria a valores próximos a US\$40 - e de aumento da produtividade e lucratividade, comum após uma empresa passar por um choque de custos adverso.

No entanto, a cotação do petróleo não recuou e as margens de lucros só vieram a esboçar recuperação após o segundo semestre do ano passado. Neste contexto, poderia haver uma mudança de tendência nos papéis das empresas do setor já para o ano de 2007? Quais as variáveis-chaves para esta mudança? Com a intenção de responder a estas questões, iremos passar a uma breve análise das principais empresas do setor, evidenciando quais as variáveischaves para cada uma delas e quais os impactos que um provável cenário para o fim de 2007 poderia causar sobre suas respectivas tendências.

\section{Desempenho recente do setor petroquímico}

Nesta seção iremos analisar o desempenho recente das empresas do setor petroquímico brasileiro listadas na Bolsa de Valores de São Paulo. As empresas listadas, o código do papel negociado, o ativo total, o nível de governança corporativa ${ }^{51}$ e o volume total (em R \$ milhões) negociado em fevereiro estão dispostos na tabela abaixo. Percebe-se que quatro empresas se destacam quanto ao ativo total e volume negociado em fevereiro de 2007 : Braskem, Copesul, Suzano Petroquímica e Unipar. A Copesul, todavia, é controlada da Braskem e não possui nível de governança corporativa reconhecido pela Bovespa, e por isso não será incluída na nossa análise setorial.

Tabela 1. Empresas listadas na Bovespa

\begin{tabular}{llrrr}
\hline Empresa & $\begin{array}{l}\text { Código } \\
\text { Bovespa }\end{array}$ & $\begin{array}{l}\text { Ativo Total } \\
\text { (R\$Bilhões) }\end{array}$ & $\begin{array}{l}\text { Nível de } \\
\text { Governança }\end{array}$ & $\begin{array}{r}\text { Volume Negociado } \\
-\begin{array}{r}\text { R\$ Milhões } \\
\text { (Fev/2007) }\end{array}\end{array}$ \\
\hline Braskem & BRKM5 & 16,3 & N1 & 375,6 \\
Copesul & CPSL3 & 2,47 & - & 44,6 \\
Elekeiroz & ELEK4 & 0,56 & - & 1,15 \\
Gpc Participações & GPCP3 & 0,7 & - & 1,57 \\
Petroflex & PEFX5 & 1,17 & - & 0,8 \\
Petroquimica Uniao & PQUN4 & 1,78 & - & 6,95 \\
Pronor & PNOR5 & 0,45 & - & 0,45 \\
Mg Poliester & RHDS3 & 1,12 & - & 9,9 \\
Suzano Petroquimica & SZPQ4 & 3,38 & $\mathrm{~N} 2$ & 29,9 \\
Unipar & UNIP6 & 2,82 & $\mathrm{~N} 1$ & 52,4 \\
\hline
\end{tabular}

Fonte: Elaboração propria a partir de dados capturados no site da BOVESPA.

51 Este indicador diz respeito aos direitos societários dos acionistas minoritários e a transparência na condução das empresas. A diferença principal entre o nível 1 (N1) e o nível 2 (N2) é que as empresas que aderirem ao N2 devem adotar arbitragem para solucionar conflitos societários, caso existam. 


\section{A BRASKEM}

A Braskem é a maior produtora de resinas termoplásticas da América Latina. Fruto da aquisição da Copene pelos Grupos Odebretch e Mariani, a empresa possui um ativo total avaliado em $\mathrm{R} \$ 16,3$ bilhões em dezembro de 2006 e possui a seguinte estrutura entre coligadas e controladas:

BRASKEM: CONTROLADAS E COLIGADAS

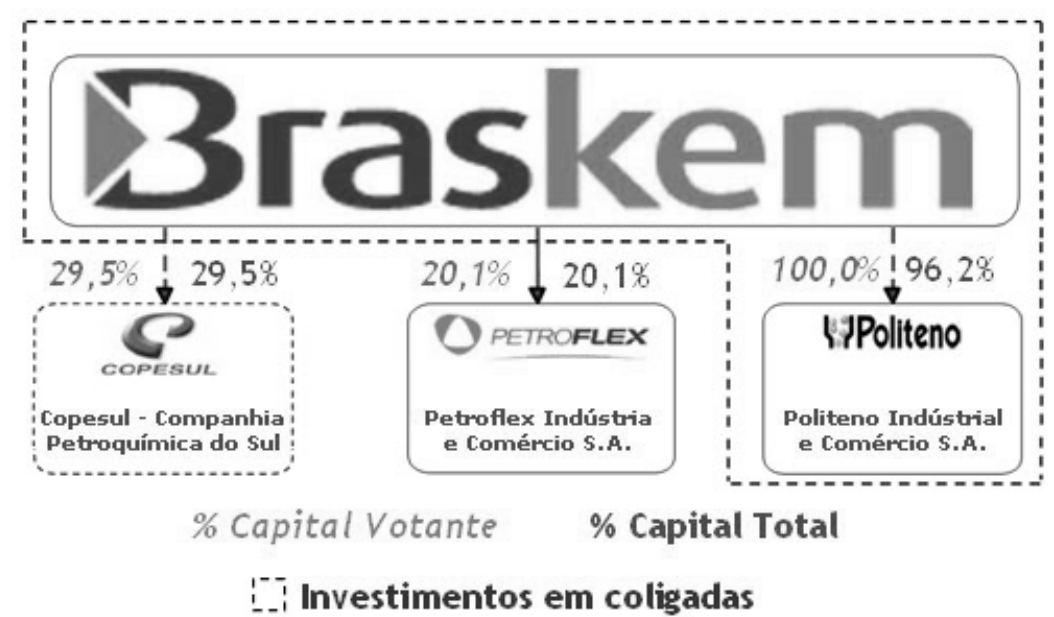

Fonte: Extraído do site da empresa.

A empresa possui um montante de endividamento bruto de $\mathrm{R} \$ 6,3$ bilhões, dos quais $49 \%$, ou R \$ 2,9 bilhões, estão denominados em moeda estrangeira. Deste modo, o efeito imediato de uma tendência à valorização cambial seria a redução das despesas financeiras da empresa, as quais seriam em parte compensadas pelas perdas associadas aos contratos de hedge para exportação e por uma redução na receita em dólares da empresa, uma vez que diferentemente do Grupo Unipar, por exemplo - mais de 30\% das vendas tiveram como destino o mercado externo no quarto trimestre de $2006^{52}$.

Os principais produtos da companhia em receita foram o polietileno e o polipropileno, que, juntos, representaram quase $50 \%$ da receita líquida no mercado externo e pouco menos de $25 \%$ no mercado interno auferida pela companhia no consolidado do $4^{\circ}$ trimestre de 2006. Adicionalmente, deve-se destacar que a Braskem investiu R $\$ 809$ milhões em 2006 e traçou uma estratégia de ampliação de sua produção com vistas a dobrar sua capacidade produtiva para cerca de 5 milhões de toneladas de resinas por ano, aproximando as novas unidades produtivas das fontes de matérias primas - por exemplo a petroquímica de

\footnotetext{
${ }^{52}$ Vale dizer, a Braskem mais do que triplicou suas exportações, em valor, entre 2002 e 2006, passando de US\$
} 0,415 para US\$ 1,4 bilhão. 
Paulínia, cidade que abriga uma refinaria da Petrobras, com capacidade de produção anual de 350 mil toneladas de polipropileno, prevista para iniciar suas operações no primeiro trimestre de 2008.

A Braskem apresentou um lucro líquido de $\mathrm{R} \$ 84$ milhões, em parte graças à redução do preço da nafta - que representa $53 \%$ do custo da produção vendida - e ao aumento de 4\% no preço das resinas ao longo de 2006.

\section{A Suzano Petroquímica}

A Suzano Petroquímica é um grupo formado pela participação nas empresas Riopol (33,33\% do capital) e Petroflex (20,12\% do capital), entre outras, e possui ativos avaliados em R \$3,4 bilhões. A companhia é controlada pela Suzano Holding, um grupo que possui negócios também no setor de papel e celulose. Em abril de 2006, a companhia vendeu sua participação na Politeno para a Braskem. É a maior produtora de polipropileno da América Latina e a segunda maior produtora de resinas termoplásticas da região, ficando apenas atrás da Braskem. Abaixo observa-se a estrutura societária da companhia:

\section{SUZANO PETROQUÍMICA: ESTRUTURA SOCIETÁRIA}

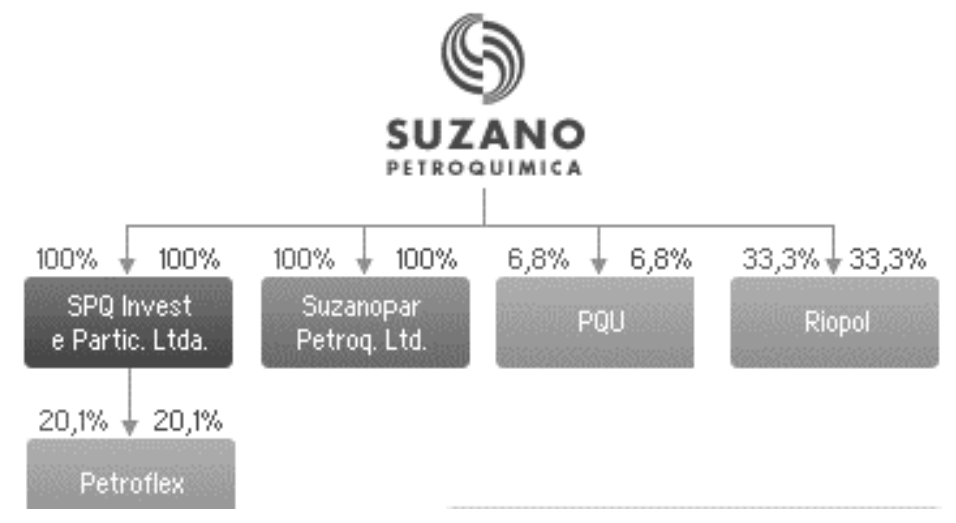

Fonte: Extraído da página da companhia.

O principal produto da companhia é o polipropileno e derivados, e cerca de $78 \%$ dos custos dos produtos vendidos é representado pelo uso do propeno. O ano de 2006 representou um período de forte recuperação da margem bruta de lucro, passando de 3,1\% no primeiro trimestre para 13,8\% no último, muito embora o lucro líquido da empresa estivesse próximo de zero, não havendo distribuição de dividendos naquele ano.

A Suzano é uma empresa com uma dívida bruta de R $\$ 1,24$ bilhão, dos quais 68\% estão atrelados à moeda estrangeira e 13,2\% vencem no curto-prazo. É uma empresa com um 152 
alto grau de alavancagem em relação ao setor, com uma relação dívida líquida - EBTIDA de 8,8, relação esta que vem diminuindo ao longo do ano - o índice chegou a 13,19 no segundo trimestre de 2006. A empresa auferiu 18\% de sua receita líquida - no valor de $\mathrm{R} \$ 2,4$ bilhão em 2006 - por meio de exportações, com a maior parte da quantidade exportada sendo direcionada para o continente africano.

Deste modo, no caso da continuidade da tendência de valorização do real frente ao dólar, o efeito sobre o balanço patrimonial da companhia, em princípio, seria ambíguo. Contudo, podemos observar que há um volume de recursos maior exposto no passivo da empresa que, através de aumento na rubrica variação cambial, poderia comprometer os resultados da empresa ao longo do tempo. Adicionalmente, o mercado do propeno está aquecido, fator que poderia comprometer a vantagem da valorização cambial sobre o custo dos produtos vendidos.

\section{O Grupo Unipar}

O Grupo Unipar é uma holding que controla diversas empresas do setor petroquímico, as quais se reportam à produção, transporte e comercialização dos mais diversos componentes químicos derivados do petróleo ${ }^{53}$. Os destaques ficam por conta da Petroquímica União, Carbocloro e Riopol. Seus principais produtos são eteno (500 mil toneladas-ano), cumeno (210 toneladas-ano), soda (283 mil toneladas-ano) e cloro (255 mil toneladas-ano).

\section{Composição do Grupo Unipar}

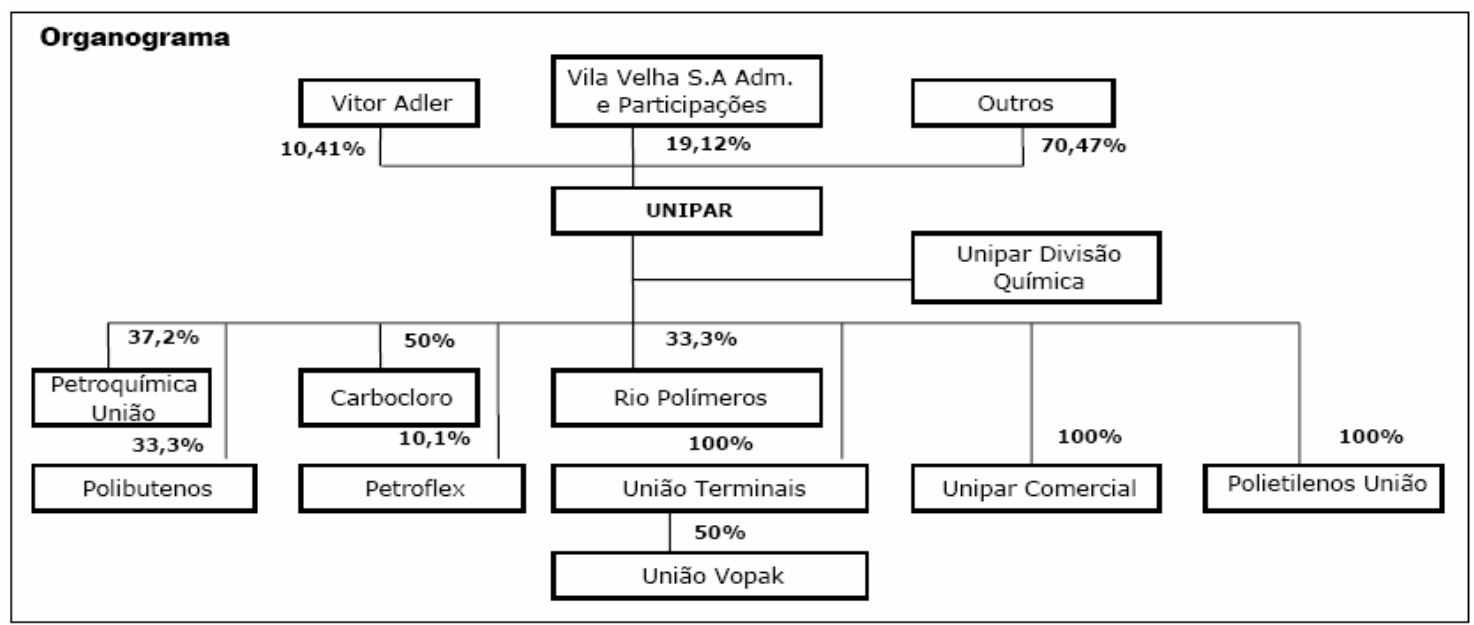

Fonte: Fitch Ratings (2007, p. 4).

53 Uma interessante descrição das empresas e suas respectivas atividades que compõem o grupo estão disponíveis no site www.unipar.ind.br e na página www.bovespa.com.br. Uma análise sobre o desempenho recente destas empresas é feito por Fitch Ratings (2007). 
Recentemente, o Grupo adotou uma estratégia de ampliação de sua atuação no setor petroquímico nacional, o que exige um montante de investimentos, os quais refletem o endividamento total da companhia de $\mathrm{R} \$ 1,1$ bilhão em setembro último, valor não desprezível em face de seu tamanho, cujos ativos totais somavam $\mathrm{R} \$ 2,8$ bilhão em setembro de 2006.

Aproximadamente $38 \%$ da dívida total da holding estão expostas a flutuações da moeda estrangeira. Neste sentido, a atual tendência de valorização do real frente ao dólar - a qual vem sendo fortemente combatida pelo Banco Central por meio de suas intervenções recentes no mercado de câmbio - ajudará sobremaneira a reduzir as despesas financeiras do Grupo $^{54}$. Vale dizer, a agência de risco Fitch Ratings, recentemente, elevou o rating da companhia de A - para A+, em função:

(...) "do histórico da performance consolidada do Grupo Unipar; da sua posição moderada de alavancagem, mesmo considerando os elevados investimentos realizados em suas controladas e subsidiárias nos últimos anos; e da capacidade da carteira de investimento do grupo em prover fluxo relevante de dividendos para a holding, não somente em ciclos favoráveis à indústria petroquímica, mas também em cenários adversos, como os observados em 2005 e 2006” (Fitch Ratings, 2007, p. 1) ${ }^{55}$.

Em 2006, a Riopol, o primeiro complexo petroquímico (produtor de polímeros) brasileiro a base de derivados de gás natural, subsidiária do Grupo Unipar, entrou em operação, após um ano de atraso. Como se trata de um project finance - o que isenta a bolding das obrigações financeiras da controlada - e dado cenário adverso que o setor atravessa, os resultados desta nova subsidiária serão refletidos apenas no médio prazo. Esta controlada deverá ser uma importante fonte de dividendos do Grupo no futuro, tendo em vista a capacidade de geração de receita dela - gerou R \$ 627 milhões entre abril e setembro de 2006 - vis-à-vis a participação da holding no negócio (33,3\% do capital da controlada).

A escalada no preço do barril de petróleo certamente inflou a estrutura de custos da empresa e, dada a estrutura de concorrência do setor do qual a companhia faz parte, impediu o pass trough e a manutenção das margens de lucros das controladas. Deve-se destacar que, o aquecimento da economia mundial causou aumento na demanda pelos produtos e serviços

\footnotetext{
54 É preciso lembrar que a maior parte da produção de suas controladas é destinada ao mercado interno e, consequentemente, o impacto de uma valorização da taxa de câmbio sobre a competitividade delas é bastante restrito.

55 Como fatores restritivos à melhora na classificação, destacam-se a natureza cíclica da indústria petroquímica; a ingerência desta sobre os preços da nafta, que, como observado recentemente, pode oscilar de forma intensa, independente do equilíbrio entre oferta e demanda dos mercados; e, ainda, os riscos associados à capacidade de repasse de preços dentro da cadeia petroquímica (cf. FITCH RATINGS, 2007, p. 1).
} 
das controladas, o que permitiu à oscilação positiva das quantidades contrabalançar, ainda que de modo tênue, a variação negativa na margem de lucro sobre a suas respectivas receitas. Como existe uma tendência de correção no preço do petróleo e que, ao longo do tempo, seja possível retomar os preços relativos anteriores à "crise do petróleo", não há qualquer indicativo de deterioração no longo-prazo para o setor petroquímico.

\section{Expectativas para o setor em 2007}

As informações descritas anteriormente pelas empresas analisadas são apresentadas na tabela abaixo. Nesta tabela foram colocadas algumas informações adicionais, como a relação preço - lucro por ação, P/L, a margem bruta e o preço justo do papel. Devemos enfatizar que a Suzano Petroquímica possui um nível de governança diferenciado e isto, de algum modo, pode afetar o preço de seu papel ${ }^{56}$.

\section{Tabela 2. Empresas Petroquímicas em dados}

\begin{tabular}{|c|c|c|c|c|c|c|}
\hline & $\begin{array}{c}\text { Margem } \\
\text { Bruta }\end{array}$ & $\mathrm{P} / \mathrm{L}$ & $\begin{array}{c}\text { Ativo } \\
\text { (R\$ Bilhões) }\end{array}$ & $\begin{array}{c}\text { Mercado } \\
\text { Externo \% }\end{array}$ & $\begin{array}{l}\text { Dívida Bruta } \\
\text { (R\$ Bilhões) }\end{array}$ & $\begin{array}{l}\text { \% Dívida } \\
\text { em US\$ }\end{array}$ \\
\hline BRKM5 & 16,94 & 48,44 & 16,3 & 29,00 & 6,3 & 49,00 \\
\hline SZPQ4 & 13,38 & $62,46^{* * *}$ & 3,38 & 18,00 & 1,24 & 68,90 \\
\hline \multirow[t]{2}{*}{ UNIP6* } & 18,62 & 28,28 & 2,82 & 0,85 & 1,13 & 38,00 \\
\hline & $\begin{array}{l}\text { Dívida } \\
\text { Curto- } \\
\text { Prazo }\end{array}$ & $\begin{array}{l}\text { Dívida } \\
\text { Líquida/ } \\
\text { Ebitda }\end{array}$ & $\begin{array}{c}\text { lucro líquido } \\
\text { em } 2006 \\
\text { (R\$milhões)* }_{*}^{*}\end{array}$ & $\begin{array}{l}\text { preço } \\
28 / 02\end{array}$ & $\begin{array}{l}\text { preço } \\
\text { justo (1) }\end{array}$ & $\begin{array}{l}\text { preço justo } \\
\text { (2) }\end{array}$ \\
\hline BRKM5 & 25,00 & 2,72 & $39 / 84$ & 13,78 & - & 3,35 \\
\hline SZPQ4 & 13,20 & 8,80 & $0 / 0$ & 4,20 & 3,25 & 0,79 \\
\hline UNIP6* & 15,20 & 2,80 & $37,7 / 47,4$ & 2,04 & 3,49 & 0,85 \\
\hline
\end{tabular}

Fonte: Elaboração própria.

$*$ Refere-se ao acumulado até 30/09/2006

** O valor antes da barra refere-se ao lucro distribuído, e o após, ao lucro líquido.

*** Valor obtido para o lucro de por ação distribuído até o $3^{\circ}$ trimestre de 2006.

56 A Suzano tomou a decisão de adesão ao N2 em Assembléia Especial de Acionistas Preferênciais Titulares, realizada em 18/11/2004, cuja pauta foi divulgada em 21/10/2004. Entre 22/10 e 18/11 daquele ano, as ações da empresa subiram de $\mathrm{R} \$ 5,52$ para $\mathrm{R} \$ 7,79$, apresentando uma valorização de quase $40 \%$. No ínicio daquele ano, o preço do papel era $\mathrm{R} \$ 2,94$, o que representa uma valorização de $87,75 \%$ até $22 / 10$. Sabe-se que há uma alta correlação entre os papéis da Suzano e da Unipar. No ano em questão, até 22/10, essa correlação foi de 0,85 , e, entre $22 / 10$ e $18 / 11,0,64$. A Unipar apresentou uma valorização de $47 \%$ até $22 / 10$ e de apenas 5,6\% entre $22 / 10$ e 18/11. Se os papéis da Suzano apresentaram uma valorização média 50\% maior do que os da Unipar no período analisado, poderíamos estimar que entre 22/10 e 18/11 as ações da Suzano deveriam subir cerca de $12 \%$ e que $28 \%$ dos $40 \%$ de variação registrado no período respondem pelo fato mudança na governança corporativa. Logo, 20,66\% do preço dos papéis da Suzano em vigor em 18/11 deveria ser atribuído à estrutura de governança corporativa diferenciada da companhia. Vale dizer, a Unipar aderiu ao N1 em 11/08/2004. 
O preço justo ${ }^{57}$ (1) foi calculado considerando apenas a relação preço-lucro da Braskem como se fosse a representativa do mercado. Podemos perceber que deveria haver um up side imediato nos papéis do Grupo Unipar e uma correção no valor dos papéis da Suzano Petroquímica. Vale dizer, se considerássemos o P/L da Dow Chemical, uma das maiores do mundo no setor petroquímico - com ativo total equivalente a US $\$ 45,6$ bilhões e margem bruta de $15,47 \%$-, cujo valor é $11,8^{58}$, teríamos os preços de Braskem, Suzano e Unipar iguais a 3,35, 0,79 e 0,85, respectivamente. Este é o preço justo (2).

Pelo perfil de cada uma das empresas, podemos constatar que, considerando estabilização do preço do petróleo, aceleração do crescimento da economia brasileira e valorização cambial como o cenário mais provável para 2007, o Grupo Unipar possui o papel com maior potencial de valorização, dados os seus fundamentos, uma vez que sua receita é quase toda denominada em R\$, seu endividamento em US\$ é o menor relativamente, é a empresa que distribuiu a maior parte de seus lucros e a que possui a melhor margem operacional bruta.

Para atestar se há, efetivamente, alguma relação entre a taxa de câmbio e o papel do setor petroquímico construiu-se uma matriz de correlação ${ }^{59}$. Nota-se que a Unipar e a Suzano exibem uma forte correlação negativa com a taxa de câmbio, isto é, um cenário de valorização cambial está associado a um aumento no preço destas ações. Já a Braskem apresentou uma correlação nula nos dois primeiros meses de 2007, o que reflete a incerteza do impacto da valorização cambial sobre suas receitas e despesas.

\footnotetext{
${ }^{57}$ Usualmente, a definição de preço justo é a seguinte: é o valor de um papel tendo como referência apenas o fluxo de caixa projetado para ele e a taxa de juros de mercado. Aqui, quando nos referimos a preço justo, estamos falando do aumento potencial de um papel tendo como referência apenas a relação $\mathrm{P} / \mathrm{L}$ de suas congêneres.

58 A Du Pont, outra grande empresa do setor petroquímico, possui ativo total de US\$ 31,77 bilhões margem bruta

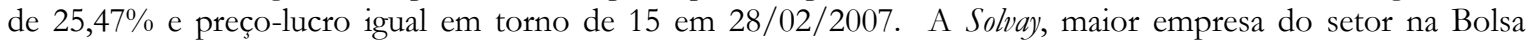
Argentina, possui ativo total de US\$ 562,67 milhões, margem bruta de $25,61 \%$ e relação preço-lucro em torno de 9 - os dados referem-se aos resultados do $3^{\circ}$ trimestre de 2006. Já a Alpek, a maior petroquímica do México, é controlada pelo conglomerado Alfa - aquela empresa responde por $53 \%$ das vendas e $50 \%$ do ativo total deste conglomerado - cujo ativo total é de US\$ 6,88 bilhões, a margem bruta de 20,94\% e o P/L de 7,55. As informaçães são da Economatica e têm como referência o preço das ações em 28/02/2007.

${ }^{59}$ Vale dizer, o simples fato da existência de correlação não diz nada a respeito da possível relação de causalidade entre as variáveis analisadas.
} 


\begin{tabular}{|c|c|c|c|c|c|c|c|c|c|c|}
\hline & & $\mathbf{M}$ & in & orrela & ăo se & Petr & vími & & & \\
\hline Variáveis & BRKM5 & CPSL3 & ELEK4 & GPCP3 & PEFX5 & PNOR5 & PQUN3 & RHDS3 & SZPQ4 & UNIP6 \\
\hline IBOVESPA & 0.103954 & 0.585949 & 0.673196 & 0.496039 & -0.013582 & 0.181122 & -0.326647 & 0.096935 & 0.724752 & 0.706472 \\
\hline CAMBIO* & 0.063929 & -0.487545 & -0.915181 & -0.722296 & 0.088191 & -0.304352 & 0.634959 & -0.225107 & -0.864150 & -0.842583 \\
\hline SELOVER & 0.209054 & -0.396254 & -0.814636 & -0.648969 & 0.092334 & -0.273599 & 0.644195 & -0.293283 & -0.696548 & -0.648358 \\
\hline TR & -0.037443 & -0.305525 & -0.819453 & -0.638568 & -0.117380 & -0.409922 & 0.775119 & -0.411220 & -0.637211 & -0.577730 \\
\hline BRENT & -0.269680 & 0.656891 & 0.649973 & 0.440822 & -0.279481 & -0.002925 & -0.086545 & -0.085032 & 0.615 & 0.564421 \\
\hline WTI & -0.460504 & 0.639551 & 0.687632 & 0.469494 & -0.493909 & -0.120158 & -0.143681 & -0.313607 & & 0.479693 \\
\hline $\mathrm{PP} * *$ & & & & & -0.007 & -0.123873 & 267 & -0.15 & & 9911 \\
\hline LL** & -0.527364 & 0.463646 & 0.623741 & 0.416597 & -0.620750 & -0.179065 & 2887 & -0.4219 & & 7448 \\
\hline BRKM5 & 1.000000 & 0.011575 & -0.194443 & -0.188490 & 0.873405 & 0.449676 & 4687 & 0.6 & -0.0 & 2100 \\
\hline CPSL 3 & 0.011575 & 1.000000 & 0.453965 & -0.060456 & 0.0270 & -0.029973 & 401 & -0.1 & & 005 \\
\hline ELEK4 & -0.194443 & 0.453965 & 1.000000 & 0.681184 & -0.196511 & 0.331869 & -0.708185 & 0.138 & 0.7 & 883 \\
\hline GPCP3 & -0.188490 & -0.060456 & 0.681184 & 1.000000 & -0.223586 & 0.22 & 6506 & 0.2498 & & 1086 \\
\hline PEFX5 & 0.873405 & 0.027028 & -0.196511 & -0.223586 & 1.000000 & 0.466011 & -0.092588 & 0.723400 & -0.0 & 8285 \\
\hline PNOR5 & & -0.029973 & 0.331869 & 0.228798 & 0.466011 & 1.00 & 0616 & & & 7959 \\
\hline PQUN3 & -0.024687 & 0.044401 & -0.708185 & -0.566506 & -0.092588 & -0.450616 & 1.000000 & -0.5 & -0.4 & 7431 \\
\hline RHDS3 & 0.615870 & -0.134037 & 0.138259 & 0.249825 & 0.723400 & 0.602392 & -0.520880 & & 0.2 & 0617 \\
\hline SZPQ4 & -0.007728 & 0.238305 & 0.726823 & 0.788088 & -0.026672 & 0.351427 & -0.485970 & 0.29 & 1.00 & 8334 \\
\hline UNIP6 & -0.072100 & 0.123005 & 0.689883 & 0.811086 & -0.118285 & 0.327959 & -0.497431 & 0.240617 & 0.958334 & 1.000000 \\
\hline$\Gamma 1$ & 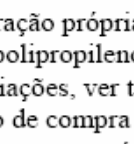 & 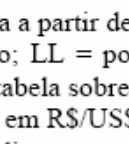 & 1 & & ד & & 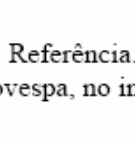 & 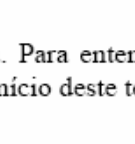 & 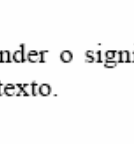 & \\
\hline
\end{tabular}

Os efeitos da tendência do índice Bovespa são muito claros para a Suzano e para Unipar, que parecem estar positivamente relacionadas a ele, enquanto a Braskem apresenta uma fraca correlação com aquele índice. Ademais, a oscilação das duas primeiras companhias parece não estar correlacionada com a da última, e há uma forte correlação entre Suzano e Unipar, conforme podemos concluir da matriz de correlação acima. A Braskem dentre as três empresas analisadas é única que apresenta uma correlação inversa à do petróleo, como seria de se esperar.

Por fim, cabe destacar que mudanças na taxa de câmbio podem causar desbalanceamentos no demonstrativo de resultados das empresas em sentidos antagônicos: para a Suzano, uma valorização cambial pode causar um aumento nas despesas financeiras vis-à-vis as receitas; já para a Braskem e principalmente para a Unipar, a valorização pode aumentar as receitas vis-à-vis as despesas.

No caso de uma valorização cambial de $10 \%$ e supondo a inexistência de contratos de hedge cambial, a receita líquida da Braskem ${ }^{61}$ diminuiria, ceteris paribus, $\mathrm{R} \$ 376,7$ milhões, enquanto que o seu estoque de dívida atrelada a moeda estrangeira convertida para reais aumentaria $\mathrm{R}$ \$ 308,7 milhões. Para a Suzano, os números seriam R \$ 44,6 milhões e $\mathrm{R} \$$ 85,46 milhões, respectivamente. Já no caso do Grupo Unipar, teríamos uma redução na despesa financeira de $\mathrm{R} \$ 42,94$ milhões e uma redução na receita de $\mathrm{R} \$ 1,96$ milhão.

${ }^{60}$ 02/01/2007 - 28/02/2007(40 Observações)

${ }^{61}$ A Braskem, no entanto, realiza significativas operações de hedge para proteger suas receitas em dólares. 


\section{Conclusão}

O ano de 2007 ainda promete ser nebuloso para as ações do setor petroquímico brasileiro. Por um lado, as empresas estão operando com uma relação preço - lucro por ação acima da média mundial do setor e, em função disso, deveriam ter seus preços corrigidos ainda mais. Por outro lado, o atual cenário para 2007, de estabilização do preço do barril de petróleo, de valorização cambial e aquecimento da economia doméstica, ajudará o setor a recompor sua margem de lucro operacional, derrubada após o choque do petróleo de 2005, o qual colocou o preço do insumo-chave do setor acima de US\$ 60 o barril.

Isto posto, o papel mais preparado para absorver uma eventual retomada da tendência de alta do setor petroquímico frente àquele cenário é o do Grupo Unipar, o qual possui forte dependência do mercado interno para geração de receitas, baixo, embora não desprezível, endividamento em dólar, um bom perfil de endividamento e um histórico de distribuição de boa parte dos lucros registrados, além de uma ousada estratégia de expansão por meio de vultosos projetos de investimentos.

Adicionalmente, tal cenário parece contribuir, em menor medida, para a valorização dos papéis da Braskem - os quais já dão sinais de sobrevalorização, especialmente se observarmos seu alto $\mathrm{P} / \mathrm{L}$-, não sendo esperadas grandes alterações para os papéis da Suzano, que, a despeito de seu nível de governança corporativa diferenciado, ainda estão claramente sobrevalorizados, dados os fundamentos da empresa vis-à-vis os de suas concorrentes. No entanto, como vimos o $\mathrm{P} / \mathrm{L}$ das empresas do setor ainda está bem acima de empresas congêneres que operam em bolsas de outros países, uma razão para olharmos com ceticismo a possibilidade de valorização daquelas ações neste ano.

\section{Referências Bibliográficas}

BOVESPA, www.bovespa.com.br. Acesso em: 07/02/2007

BRASKEM, www.braskem.com.br. Acesso em: 30/01/2007

ECONOMÁTICA, www.economatica.com.br. Acesso em: 08/02/2007

FITCH RATINGS. "Relatório Analítico Unipar". Disponível em: www.unipar.ind.br. Acesso em: 02/02/2007.

GRUPO UNIPAR, www.unipar.ind.br. Acesso em: 05/02/2007

IPEADATA, www.ipeadata.gov.br. Acesso em: 05/02/2007

LEMOS, B.P. (2007). "Comportamento Recente do Índice Bovespa”. Curitiba: Economia \& Tecnologia, 3 (4).

LME, www.lme.com. Acesso em: 05/01/2007

SUZANO PETROQUÍMICA, www.suzanopetroquimica.com.br. Acesso em: 04/02/2007 